\title{
Quality evaluation of dietetic sucrose-free sponge cakes with einkorn wholemeal flour (Triticum Monococcum I.)
}

\author{
Zhivka Goranova', Marianna Baeva², Todorka Petrova ${ }^{1}$ \\ 1 - Institute of Food Preservation and Quality, Plovdiv, Bulgaria \\ 2 - University of Food Technology, Plovdiv, Bulgaria
}

\begin{abstract}
The possibility of the use of einkorn wholemeal flour, which application is almost unknown in sucrose-free sponge cake, is presented in this article. Four types of sucrose-free sponge cakes production by a substitution of wheat flour with einkorn wholemeal flour (with 25\%, 50\%, 75\% and 100\% einkorn wholemeal flour). The sponge cake batters recipe composition is specified as the physical characteristics of the goods are determined. The methods of descriptive sensory analysis are used for a comparative analysis of the new and the control sponge cakes sugar free. The newly obtained baker's goods are characterized with very good quality properties in comparison with those of the cake without einkorn wholemeal flour (the control cake-sample). On the grounds of the received results it can be expected a potential consumer interest in pastry food products enriched with functional components.
\end{abstract}

Key words: sucrose-free, sponge, cake, einkorn.

Corresponding author: Zhivka Goranova

E-mail: jivka_goranova@abv.bg

DOI: $10.24263 /$ RES-2019-5

\section{Introduction}

Cakes are sweet baked goods that are consumed by people from all over the globe. Cake is a complex system. For the success of a cake, the batter should have appropriate and properly balanced formula as well as suitable ingredients. Different types of cakes need different kind of ingredients and formula balance. Each ingredient has its own special functionality.

The number of people suffering from obesity, cardiovascular disease and type-2diabetes, increased enormously. The published statistic is shocking: 1.9 billion adults over the age of 18 and 41 million children under the age of 5 are overweight or obese [1]. The reduction of sugar in sweet bakery products is challenging, however, since sugar fulfils more functions than only sweetness and flavour. Sugar also influences the colour of the cake. Sugar is one of the essential ingredients in biscuits and cakes, not just to ensure taste and flavour, but also to give products their unique texture. It is 
essential to investigate the interactions of sugar with the main ingredients in baked goods and to understand the role of sugar in different products. By now two main strategies to reduce sugar with a promising result have been introduced: firstly, the replacement of sugar by a sweet bulking agent, such as polyols, and secondly, sugar substitution by a combination of non-sweet bulking agents and high-intensive sweeteners. A total sugar replacement in sponge cake (sugar content of $23.19 \%$ based on the whole recipe) by the combination of fructose, polydextrose and acesulfame- $\mathrm{K}$ or aspartame showed high consumer acceptance and reduced calories by $40 \%$ [2].

Mannitol, sorbitol, maltitol, erythritol, isomalt, xylitol and lactitol are considered as food additives and listed as a ' $E$ ' number in the list of ingredients. They are only allowed to be added as sweeteners in products which are either 'energy-reduced' or have 'no additional sugar' [3]. Foods containing more than $10 \%$ added polyols has to be claimed as 'excessive consumption may produce laxative effects' [2].

Einkorn (Triticum monococcum L.) is a diploid hulled wheat appreciated for its excellent nutritional properties, including high protein, carotenoids, $\beta$-glucans and antioxidants contents, and as such it is a promising candidate for the development of functional bakery products. Einkorn-enriched cookies had higher ash, polyphenols, carotenoids, antioxidants and beta-glucans content than pure wheat flour cookies, and might possibly be classified as functional foods. The addition of different flours to bakery products creates an opportunity to combine beneficial technological properties with beneficial biological health promoting properties. Addition of different flours to bakery products creates an opportunity to combine beneficial technological properties with beneficial biological health promoting properties. Since the wholemeal products consumption became a part of well-being trends, addition of natural components, incorporating the biological activity, would enhance food's quality and pro-health value. Designed sponge cakes with functional ingredients would be the answer to the increasing interest in health promoting aspects and nutritional value of food [4].

The objective of this article is the investigation of the influence of einkorn wholemeal flour on physical and sensory characteristics of sucrose-free sponge cakes.

\section{Materials and methods}

The products used in the preparation of the sucrose-free sponge cakes without and with einkorn wholemeal flour: wheat flour, wheat starch, eggs, distilled water, sodium bicarbonate, citric acid, sorbitol, encapsulated aspartame, einkorn wholemeal flour. The amounts of sorbitol and that of the high-potency sweetener (encapsulated aspartame). The cake batter (control batter) was made according to the technological scheme described in a patent form № 463 of 02.07.2001 - Bulgaria [5], and a doublebowl mixing procedure was used. The recipe for making batter included preliminary separation of egg whites and yolks. The egg whites were whipped by a mixer at easy speed increasing from $1(19 \mathrm{rpm})$ to $3(31 \mathrm{rpm})$ grade. The egg yolks were mixed with a half of water amount and whipped at speed of 1 grade. Then the rest water amount 
warmed up to $18-20^{\circ} \mathrm{C}$, sodium bicarbonate, citric acid and sorbitol was added. The mixture was whipped again at speed of 1 grade and the screened wheat starch was added under continuous mixing. The egg white foam was incorporated to the egg yolk mixture. Finally the screened wheat flour and encapsulated aspartame were added to the mixture. The sponge cakes were baked in a metallic pan containing $95 \mathrm{~g}$ of batter and placed in an electric oven for $30 \mathrm{~min}$ at $180^{\circ} \mathrm{C}$.

The specific gravity of the sponge cake batter was calculated by dividing the weight of a standard batter cup to the weight of an equal volume of distilled water at batter temperature $\left(20.0 \pm 0.5^{\circ} \mathrm{C}\right)$ [6]. The physical characteristics of the sponge cakes were determined $2 \mathrm{~h}$ after baking. Volume was measured by the small uniform seed displacement method [7], and and porosity was assessed according to the Bulgarian State Standard method [8]. The specific volume was expressed as the ratio of the sponge cake volume to its mass. The water-absorbing capacity of the sponge cake was measured by the extent of biscuit swelling according to the Bulgarian State Standard method [9]. Total sample moisture was determined after drying the sample at $105^{\circ} \mathrm{C}$ up to a constant weight according to the standard method [10].

Sensory characteristics: The descriptive test for a quantitative sensory profiling was used to establish the sensory characteristics (shape, colour, cell size and uniformity, odour, crumb tenderness) of the sponge cakes, $6 \mathrm{~h}$ after baking, following the ISO 8586:2014 and ISO 13299:2016 methods [11-12]. The sponge cakes samples were ready $1 \mathrm{~h}$ before the evaluation. Samples of different cakes were kept in coded plates covered with aluminium foil. Twelve trained panelists were selected to guarantee the evaluation accuracy. The intensity of each sensory characteristic was recorded on a ten-point linear scale after $1 \mathrm{~h}$ orientation sessions of the panelists, where they specified terminology and anchor points on the scale. The coded samples were shown simultaneously and evaluated in random order among the panelists.

\section{Results and discussion}

The developed recipe composition of sucrose-free sponge cakes with einkorn wholemeal flour was prepared by the replacement of wheat flour with einkorn wholemeal flour in quantity $25 \%, 50 \%, 75 \%$ and $100 \%$. The stages of technology were kept because of their easy fulfillment and the considerably small duration of the technological cycle. The sponge cakes containing einkorn wholemeal flour were processed at constant regime of baking concurrent with that of the control sample, which according to the technological instruction was baked for $30 \mathrm{~min}$ at $180^{\circ} \mathrm{C}$.

Changes in the physical characteristics of batters and sponge cakes containing einkorn wholemeal flour in different amounts are summerized in Table 1. The specific gravity of cake batter affects volume, porosity, water-absorbing capacity of the sponge cake and is important for the formation of crumb texture of the cake. The sponge batter, obtained by replacing wheat flour with einkorn wholemeal flour $(50 \%, 75 \%$ and $100 \%)$, had a lower specific gravity than that of the control batter. Lower specific 
gravity is an indicator of more aeration, which is a desired property of cake batter. No significant differences were found in the specific gravity of the batter values between the control batter $(0.65 \pm 0.01)$ and $25 \%$ einkorn wholemeal flour sponge cake batter $(0.66 \pm 0.01)$, which could encourage the formation of larger bubbles during baking and therefore result in greater product height and volume. In this studying the volume of cake-sample $\left(185.00 \pm 10.00 \mathrm{~cm}^{3}\right)$ was smaller than this of cakes containing $25 \%, 50 \%$ and $75 \%$ einkorn wholemeal flour, as the volume of the cake with $75 \%$ einkorn wholemeal flour $\left(230.00 \pm 8.16 \mathrm{~cm}^{3}\right)$ is the largest, while the cake with a higher quantity of einkorn wholemeal flour $(100 \%)$ had the smallest volume $\left(160.00 \pm 15.00 \mathrm{~cm}^{3}\right)$. Ronda, Gómez, Blanco \& Caballero (2005) studied the effect on sponge cake volume, colour and texture properties of total replacement of sucrose by seven bulking agents, including PD. The results showed that xylitol-PDwas a good option to replace sugar.Specific volume of cakes varied between $2.67 \pm 0.35 \mathrm{~cm}^{3} / \mathrm{g}$ and $3.76 \pm 0.27 \mathrm{~cm}^{3} / \mathrm{g}$. For the cake with $100 \%$ einkorn wholemeal flour, was characterized with a smaller specific volume $(2.67 \pm 0.35)$ and porosity $(64.81 \pm 4.14)$ were measured. The greatest porosity was observed in the cake with $75 \%$ einkorn wholemeal flour. In comparison with the control $(47.33 \pm 2.52 \mathrm{PU}$ and $80.33 \pm 8.02 \mathrm{PU})$, a decrease in springiness and shrinkage was found when wheat flour was replaced by einkorn wholemeal flour. It was observed that the total moisture content of the sponge cakes with einkorn wholemeal flour decrease. The water-absorbing capacity of the cake control (317.22 \pm $13.14 \%$ ) is the lowest than that of the cakes with different levels of einkorn wholemeal flour.

Table 1

Physical characteristics of sucrose-free sponge cakes

\begin{tabular}{|l|c|c|c|c|c|}
\hline \multicolumn{1}{|c|}{$\begin{array}{c}\text { Physical } \\
\text { characteristics }\end{array}$} & \multicolumn{5}{|c|}{ Sponge cake type } \\
\cline { 2 - 6 } & Control & $\begin{array}{c}\text { with 25\% } \\
\text { EWF }\end{array}$ & $\begin{array}{c}\text { with 50\% } \\
\text { EWF }\end{array}$ & $\begin{array}{c}\text { with 75\% } \\
\text { EWF }\end{array}$ & $\begin{array}{c}\text { with 100\% } \\
\text { EWF }\end{array}$ \\
\hline $\begin{array}{l}\text { Specific gravity } \\
\text { (for batter) }\end{array}$ & $0.65 \pm 0.01$ & $0.66 \pm 0.01$ & $0.62 \pm 0.02$ & $0.63 \pm 0.03$ & $0.63 \pm 0.01$ \\
\hline Volume, cm ${ }^{3}$ & $185.00 \pm 10.00$ & $208.75 \pm 6.29$ & $210.00 \pm 8.16$ & $230.00 \pm 8.16$ & $160.00 \pm 15.00$ \\
\hline $\begin{array}{l}\text { Specific volume, } \\
\text { cm }^{3} \text { /g }\end{array}$ & $3.48 \pm 0.18$ & $3.45 \pm 0.16$ & $3.69 \pm 0.26$ & $3.76 \pm 0.27$ & $2.67 \pm 0.35$ \\
\hline Porosity,\% & $66.67 \pm 3.02$ & $68.06 \pm 3.51$ & $68.52 \pm 2.14$ & $73.15 \pm 1.85$ & $64.81 \pm 4.14$ \\
\hline Springiness, PU & $47.33 \pm 2.52$ & $27.75 \pm 2.50$ & $40.00 \pm 12.49$ & $28.75 \pm 2.50$ & $31.33 \pm 10.21$ \\
\hline Shrinkage, PU & $80.33 \pm 8.02$ & $71.25 \pm 3.10$ & $70.00 \pm 5.00$ & $74.75 \pm 1.71$ & $59.67 \pm 6.11$ \\
\hline $\begin{array}{l}\text { Water-absorbing } \\
\text { capacity,\% }\end{array}$ & $317.2 \pm 13.14$ & $372.55 \pm 7.86$ & $379.18 \pm 10.93$ & $342.07 \pm 4.87$ & $325.54 \pm 11.68$ \\
\hline Total moisture, \% & $46.81 \pm 0.17$ & $40.00 \pm 2.10$ & $42.55 \pm 0.50$ & $36.17 \pm 1.14$ & $41.39 \pm 1.60$ \\
\hline
\end{tabular}

${ }^{1}$ The values are mean $\pm \mathrm{SD}(\mathrm{p} \leq 0.05)$.

${ }^{2}$ The temperature of the batter is on the average $20.0 \pm 0.5^{\circ} \mathrm{C}$.

${ }^{3}$ PU - Penetrometer Units. 
Sensory analysis evaluations were performed in order to determine the optimum sensory characteristics of sponge cakes with regard to the panelists' preferences. The results of the sensory evaluation are given in Figure 1. Ratings test revealed that sensory characteristics including shape, colour, cell size and uniformity, odour and crumb tenderness were perceived without significant differences between the control cake and those supplemented with different concentrations of einkorn wholemeal flour. In terms of their shape, the cakes with the addition of einkorn wholemeal flour were perceived very well. Lin \& Lee (2005) studied the effect of replacement of sucrose by a mixture of sucralose and a type of indigestible dextrin in chiffon cakes obtaining good results in physical and sensory properties in samples with less than 50\% replacement.
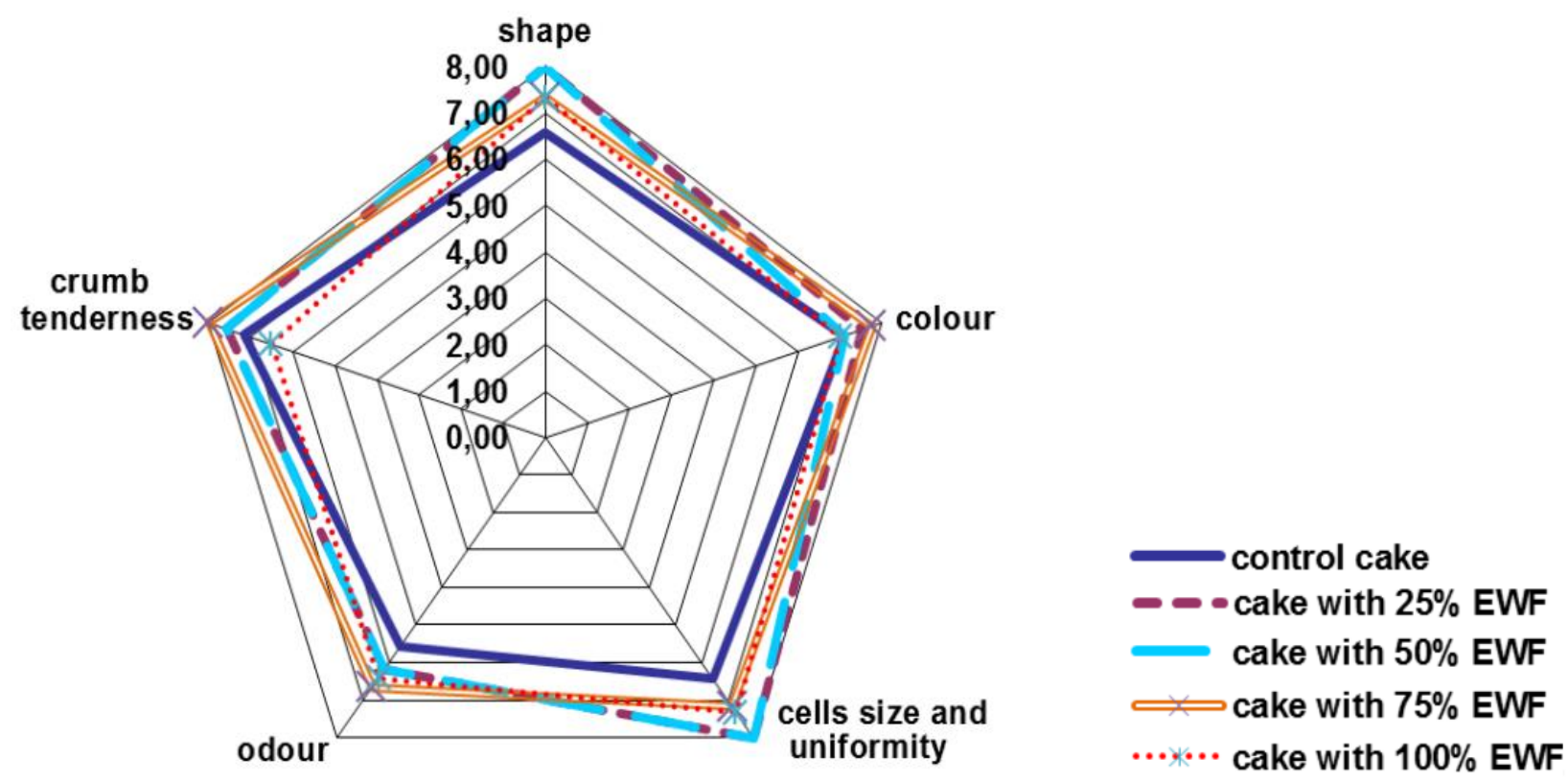

Figure 1. Sensory characteristics of sucrose-free sponge cakes ${ }^{1}$

The all cakes have a crust and crumb with more pronounced light-yellow colour due to the presence of the dying components in the yolks of egg and einkorn (especially carotenoids and lutein). The data showed that size and uniformity of cells and crumb tenderness of cakes with einkorn wholemeal flour is bigger than that of the cakecontrol. The cells of the new sponge cakes with einkorn wholemeal flour were small and equal, uniformly distributed in the crumb, and were thin-walled. Amin et al. (2016) study sugar-free cookies fortified with Pea (Pisum sativum L.) flour, soya bean (Glycine $\max$ L.) flour and oat (Avena sativa L.) flakes, sensory evaluation of cookies showed that with regard to color, taste, flavor and texture, cookies with 5\% to $10 \%$ pea flour and soya bean flour scored highest. The mean score of sponge cakes with einkorn wholemeal flour evaluated in terms of crumb tenderness was higher than that of the cake control. 


\section{Conclusion}

The physical and sensory characteristics of the sucrose-free sponge cakes with einkorn wholemeal flour are juxtaposed with those of the control cake. On the grounds of this we consider that newly prepared sponge cakes containing einkorn wholemeal flour are suitable as intermediate products in confectioneries designed for functional nutrition.

\section{References}

1. World Health Organization (2017).

2. Sahin A., Zannini E., Coffey A., Arendt E. (2019), Sugar reduction in bakery products: Current strategies and sourdough technology as a potential novel approach, Food Research International, 126, 108583, DOI: 10.1016/j.foodres.2019.108583

3. Regulation (EU) No 1129/2011. (2011), Amending Annex II to Regulation (EC) No 1333/2008 of the European Parliament and of the Council by establishing a Union list of food additives, L295 Official Journal of the European Union $\S(2011)$.

4. Goranova Zh., Baeva, M., Slavova, V. (2015), Influence of non-traditional flours with functional properties on changes of sponge cakes during storage, Indian Journal of Applied Research, 5(10), pp. 492-494

5. Baeva M.R., Terzieva V.V. (2001), Dietetic Batter. BG Patent 463, July 2, 2001.

6. AACC (American Association of Cereal Chemists) (1983), Approved methods of the AACC. Method 10-95. 8th ed. St. Paul, Minn, USA: AACC International

7. AACC (2000), Method 10-05.01. Guidelines for measurement of volume by rapeseed displacement. Approved method of the American Association of Cereal Chemists, International. Approved Methods of Analysis, 11th edition. St. Paul, MN: AACC International

8. Bulgarian State Standard (1979), Method 3412-79. Retrieved on 01 September 2019 from http://www. bds-bg.org/bg/standard/?natstandard_document_id=13099

9. BSS. (1981). Method for determination of water absorption ability of the biscuits. Bulgarian State Standard, 15221-81.

10. AACC (1999), Method 44-15.02. Moisture - Air-Oven Methods. Approved method of the American Association of Cereal Chemists, International. Approved Methods of Analysis, 11th Ed. St. Paul, MN: AACC International

11. ISO 8586:2014(2014), Sensory analysis - General guidelines for the selection, training and monitoring of selected assessors and expert sensory assessors.

12. ISO 13299:2016 (2016), Sensory analysis - Methodology - General guidance for establishing a sensory profile.

13. Ronda, F., Gómez, M., Blanco, C. A., \& Caballero, P. A. (2005), Effects of polyols and nondigestible oligosaccharides on the quality of sucrose-free sponge cakes, Food Chemistry, 90(4), pp. 549-555. 
Resource and Energy Saving Technologies of Production and Packing of Food Products as the Main Fundamentals of Their Competitiveness: Proceedings of the 8th International Specialized Scientific and Practical Conference, September 12, 2019. Kyiv, Ukraine

14. Lin, S. D.,\&Lee, C. C. (2005), Qualities of chiffon cake prepared with indigestible dextrin and sucralose as replacement for sucrose, Cereal Chemistry, 82(4), pp. 405-413.

15. Amin, T., Bashir, A., Dar, B. N., Naik, H. R. (2016), Development of high protein and sugar-free cookies fortified with pea (Pisum sativum L.) flour, soya bean (Glycine max L.) flour and oat (Avena sativa L.) flakes, International Food Research Journal, 23(1), pp. 72-76. 